\title{
Progressive Resistance Exercise Training Attenuated Renal Damages, but did not improve Muscle Force in STZ-Induced Diabetic Rats
}

Kleiton Augusto Santos Silva ${ }^{1 *}$, Ralmony de Alcântara Santos ${ }^{2}$, Marcelo Rocino Arlotti ${ }^{1}$, Luciana Jorge ${ }^{1}$, Rafael da Silva Luiz ${ }^{1}$, Rodolfo Rosseto Rampaso', Tatiana Sousa Cunha ${ }^{2}$, and Nestor Schor ${ }^{1 *}$

${ }^{1}$ Nephrology Division, Department of Medicine, Federal University of Sao Paulo, Sao Paulo, SP, Brazil

${ }^{2}$ Science and Technology Institute, Federal University of Sao Paulo, Sao Jose dos Campos, SP, Brazi

\begin{abstract}
A type of exercise (Resistance Exercise Training - RET) that is markedly applied to increase muscle mass has been prescribed to prevent muscle atrophy from catabolic conditions such as, diabetes and chronic kidney disease. However, how this type of exercise modulates renal system remains unclear. It prompted us to apply progressive RET to STZ-induced diabetes rats in order to investigate renal environment. Progressive RET was applied to Wistar rats under following exercise program: 6 to 12 climbs/day, 5 days/week, 8 weeks, at 50 to $80 \%$ of maximal loading test. After streptozotocin injection, animals were divided into four groups: two control groups (non-exercised and exercised) and two diabetic groups (non-exercised and exercised) with 4 to 6 rats/group. Kidney weight (KW), muscle weight, proteinuria and protein level (assessed by Western blot and multiplex technology) were determined. It was found that RET did not protect exercised diabetic animals from loss of muscle mass. RET did not influence the performance in maximal loading test in diabetic groups $(p>0.05)$; additionally exercised diabetic animals did not recover body weight ( $p>0.05)$. KW was preserved in exercised diabetic animals meanwhile proteinuria was lowering as well $(15.83 \pm 2.6 \mathrm{mg} / 24 \mathrm{~h})$ when compared to diabetic group $(37.66 \pm 3.2 \mathrm{mg} / 24 \mathrm{~h}, \mathrm{p}<0.05)$. We assessed upstream and downstream of mTOR and found significant decreases in PI3K, p-Akt and p-4EBP1 in kidneys of exercised diabetic animals $(p<0.05)$. Moreover, we observed that kidney protein level of TGF $\beta-1$ was markedly decreased in exercised diabetic animals. Under progressive RET program, kidneys may be functionally protected and mTOR-signaling pathway plays important role on renal environment. However, skeletal muscle showed no improvement under this program, suggesting different mTOR modulation among renal and muscle functions.
\end{abstract}

Keywords: PI3K/Akt/mTOR-signaling pathway; Renal hypertrophy; Podocin; Fibrosis; Exercise prescription; Ladder climb; Muscle force

\section{Introduction}

Diabetic Nephropathy (DN) affects worldwide population and is the leading cause for end-stage renal disease. This complication is characterized by morphologic changes, including renal hypertrophy, augmented fibrosis and inflammation, increased proteinuria and also by a markedly impairment of renal function [1-3]. Increased kidney mass (i.e. renal hypertrophy) in $\mathrm{DN}$ is, in part, due to activation of mTOR (mammalian target of rapamycin, currently known as mechanistic target of rapamycin).

mTOR regulation includes cell growth, cell cycle, autophagy, and metabolism in several tissues such as, kidneys, skeletal muscle, vessels, heart and tumors. mTOR is an evolutionary conserved serine/threonine kinase and there are two complexes of mTOR that are functional and structurally different; complex 1 (mTORC1) is rapamycin (mTORC1 inhibitor) sensitive and is responsible for cell growth and proliferation. The complex 2 (mTORC2) does not respond to acute treatment of rapamycin and affects cell polarity and actin cytoskeleton; although both complexes can be activated by growth factors such as insulin and IGF-1, only mTORC1 responds to amino acids [4-6]. It is known that mTORC1 upstream regulation includes important proteins such as, lipid kinase phosphatidylinositol 3-kinase (PI3K), phosphatase and tensin homolog on chromosome 10 (PTEN), Akt (also known as protein kinase B) and tuberous sclerosis complex $1 / 2$ (TSC1/2). The process begins with activation of PI3K that phosphorylates PIP2 to PIP3; PTEN dephosphorylates PIP3 back to PIP2 and prevents Akt activation [7]. However, failure to increase PTEN expression culminates in increased Akt phosphorylation, and TSC1/2 (downstream of Akt) is also phosphorylated releasing mTORC1 from its inhibiting action. Downstream of mTORC1 is characterized by activation of ribosomal protein and S6 kinase and phosphorylation of eukaryotic initiation factor 4E biding protein 1 (4EBP1), which increase cell growth [8-10].

RET is an important and essential applied method to gain muscle mass and it has been markedly accepted as treatment for skeletal muscle atrophy under catabolic conditions [4,5,11]. In skeletal muscle, mTORsignaling pathway have been shown to play crucial role in hypertrophy $[12,13]$. Although, the joint position statement by American College of Sports Medicine (ACSM) and American Diabetes Association provided important information regarding prescription of RET and skeletal muscle adaptation in diabetes [6], little is know regarding how progressive RET modulates renal environment.

Hornberger et al. [14] demonstrated that a ladder climb apparatus is a well tool to improve skeletal muscle hypertrophy in normal rodents. We used the same apparatus to study the mechanism by which progressive RET might influence renal environment in diabetic rats. Additionally, because it is not fully understood how RET modulates renal system in diabetes mellitus, we believe that progressive RET might

*Corresponding author: Nestor Schor and Kleiton Augusto Santos Silva, Nephrology Division, Department of Medicine, Federal University of Sao Paulo, Rua Botucatu, $740,2^{\circ}$ andar, Disciplina de Nefrologia, 04023-900, São Paulo, SP, Brazil, Tel: +55 11 59041699; Fax: +55 11 59041684; E-mail: nestor.schor@unifesp.br, ksilva@unifesp.br

Received August 26, 2014; Accepted October 21, 2014; Published October 23 2014

Citation: Silva KAS, de Alcântara Santos R, Arlotti MR, Jorge L, da Silva Luiz R, et al. (2014) Progressive Resistance Exercise Training Attenuated Renal Damages, but did not improve Muscle Force in STZ-Induced Diabetic Rats. J Diabetes Metab 5: 461 doi:10.4172/2155-6156.1000461

Copyright: $\odot 2014$ Silva KAS, et al. This is an open-access article distributed under the terms of the Creative Commons Attribution License, which permits unrestricted use, distribution, and reproduction in any medium, provided the original author and source are credited. 
modulate kidney environment through PI3K/Akt/mTOR-signaling pathway.

\section{Material and Methods}

\section{Animals}

Two months old male Wistar rats ( $\mathrm{n}=4$ to 6/group) obtained from Center of Biology and Medicine for Experimental Models of Federal University of Sao Paulo (CEDEME), were used throughout this study, and randomly assigned into 4 groups: two control groups (nonexercised and exercised) and two diabetic groups (non-exercised and exercised). Animals were fed standard laboratory chow and given tap water ad libitum while housed (4-5 per cage) in a temperature and humidity-controlled room $\left(22^{\circ} \mathrm{C}\right.$ and $\left.60 \pm 5 \%\right)$, with a $12: 12 \mathrm{~h}$ lightdark cycle (lights on at 7 a.m.). All experimental procedures followed Institutional Guidelines for Care and Use of Laboratory Animals, and the Ethic's Committee of Federal University of Sao Paulo, Brazil approved the protocols (Process number: 0185/11).

Diabetes was induced after $12 \mathrm{~h}$ fasting by a single tail vein injection of streptozotocin (STZ, 50mg kg-1 body weight; Sigma, Chemical, St. Louis, MO; in freshly prepared $0.01 \mathrm{M}$ citrate buffer, $\mathrm{pH} 4.5)[15,16]$. Control animals were injected with citrate buffer only. Following this period, animals were kept for 3 days with free access to food and water. STZ-injected animals exhibited massive glycosuria and hyperglycemia within few days, and diabetes was confirmed by measuring fasting blood glucose concentration 5 days after drug injection. Fasting blood glucose was determined in blood samples obtained by tail prick, by using a strip operated glucometer (Accu-Check ${ }^{\circledR}$ Sensor, Roche, Swiss) and rats were considered diabetic if they had fasting plasma glucose $>250 \mathrm{mg} / \mathrm{dL}$. In those animals we measured basic parameters such as body weight and renal function; we also measured protein level by western blot and multiplex technology. For that purpose, animals were anesthetized (ketamine $80 \mathrm{mg} / \mathrm{kg}$ + xylazine $12 \mathrm{mg} / \mathrm{kg}$, IP) and a peritoneal incision was made to carefully remove kidneys. Subsequently, kidneys were weighted and immediately placed in liquid nitrogen. Next, kidneys were storage in $-80^{\circ} \mathrm{C}$.

\section{Western blotting and reagents}

Total kidney (30 to $50 \mathrm{mg}$ ) was mixed with $1 \mathrm{~mL}$ of RIPA buffer. After protein concentration determination by BSA method, proteins ran in a SDS-page electrophoresis gel and were next electrotransferred to a $0.22 \mu \mathrm{m}$ PVDF membrane. Membranes were blocked (5\% BSA) and incubated in primary antibodies $(1: 1000)$ at $4^{\circ} \mathrm{C}$ with gentle mixing overnight. Next, membranes were incubated in secondary antibodies (1:10000) at room temperature. Following the incubation, ECL detection was applied. Antibodies anti-PI3K p85 subunit, antiGAPDH, and anti-total 4E-BP1 were purchased from Millipore (Temecula, CA, USA). Antibodies anti-total Akt, and anti- $\beta$-actin were purchased from Cell Signaling Technology (Beverly, MA, USA). Antibody anti-phospho 4E-BP1 was purchased from Calbiochem (Darmstadt, Germany). Antibody anti-podocin and anti-phospho Akt were purchased from Santa Cruz Biotechnology (Santa Cruz, CA).

\section{Multiplex evaluation}

We used kidney sample to assess transformer growth factor beta 1 (TGF $\beta$-1) by multiplex assay (Milliplex xMAP multiplex technology - Millipore Billerica, MA, USA). Anti-TGF $\beta$-1-labeled beads were re-suspended and aliquoted into a pre-washed 96 well filter plate. Twenty-five microliters of kidney sample or standards/controls were mixed with the beads in the assay buffer and incubated overnight at $4^{\circ} \mathrm{C}$. Subsequently, the plate was incubated with biotinylated detection antibody and streptavidin-phycoerythin solution and run on the Luminex 200 instrument (Luminex, Austin, TX).

\section{Resistance exercise training}

Ladder climb was the method we used to exercise animals. In the past, Hornberger et al. [14] developed a specific training method for rodents. We used that apparatus to perform resistance exercise training in exercised control and exercised diabetic animals. First, all animals were adapted (one week) to the ladder for apparatus recognition and also to improve climb ( 3 to 6 climbs, 1 minute of rest between climbs). Second, all animals were submitted to a test to determine the exercise training prescription, and every two weeks in order to adjust prescription and to evaluate exercise training protocol efficiency. Test consisted of climbs until the animals were not able to complete it, and the last successful climb was considered $100 \%$ of maximal produced force to prescribe exercise training protocol. The test was performed in all groups. After the test, we designed a prescription that consisted in 50 to $80 \%$ of $100 \%$ of maximal obtained produced force. Initial resistance exercise training program consisted of 6 climbs, $50 \%$ of maximal produced force and 1 minute of resting between climbs. Every week, we increased the number of climbs until 12 (adjustment were performed every two weeks based on a new test). After animals reached 12 climbs, we progressively increased the intensity of training (based on percentage). Final exercise program was 12 climbs, $80 \%$ of maximal produced force, and 1 minute of resting between climbs. One day after the last RET section, animals were submitted to the last test to evaluate the efficiency of resistance exercise training program (Figure 1).

\section{Renal function and urinary protein content}

Two days after the last RET session, rats were housed in individual metabolic cages, and $24 \mathrm{~h}$ urine was collected and centrifuged at 3,000 $\mathrm{rpm}$. Creatinine and proteinuria were analyzed. The animals (all groups) were anesthetized at the end of the protocol period (ketamine $80 \mathrm{mg} / \mathrm{kg}+$ xylazine $12 \mathrm{mg} / \mathrm{kg}$, IP) to collect serum retro-orbital plexus ( $400 \mu \mathrm{L}$ of blood). All efforts were made to minimize suffering. To evaluate renal function (i.e. creatinine clearance) and proteinuria, a semi-automatic biochemical analyzer (model BIO-200F, São Paulo, São Paulo, Brazil) was used; creatinine levels were measured by the Jaffé method (Creatinina K - Colorimétrico, Picrato alcalino, Labtest Diagnóstica SA, Minas Gerais, Brazil), and proteinuria were monitored by a Sensiprot Protein Assay Kit (Labtest Diagnóstica SA, Minas Gerais, Brazil).

\section{Statistical analysis}

Results are expressed as means \pm SEM. Statistical differences were determined by two-way analysis of variance (Two-way ANOVA) and Bonferroni post-hoc test; It was used GraphPad Prism 6.0 Software to analyze the data. Differences were considered significant at $\mathrm{p}<0.05$.

\begin{tabular}{cccc}
$\begin{array}{c}6 \text { to } 7 \text { climbs } \\
50 \%\end{array}$ & $\begin{array}{c}8 \text { to } 9 \text { climbs } \\
60 \%\end{array}$ & $\begin{array}{c}9 \text { to } 10 \text { climbs } \\
70 \%\end{array}$ & $\begin{array}{c}11 \text { to } 12 \text { climbs } \\
80 \%\end{array}$ \\
\hline 2 weeks $\uparrow$ & 2 weeks $\uparrow 2$ weeks $\uparrow$ & 2 weeks $\uparrow$
\end{tabular}

Figure 1: Progressive resistance exercise training time-line. Rats were trained for 8 weeks and subjected to maximal loading test each two weeks to improve training adaptation and prescription. 


\section{Results}

\section{Progressive RET in diabetic animals prevents increased renal hypertrophy}

STZ-induced diabetes increases kidney weight gain. This characteristic increase in kidney weight (measured by hypertrophy index) was found in diabetic group, and surprisingly progressive RET prevented it in diabetic exercised animals (Figure 2A; $\mathrm{p}<0.05$ ). Because the effects of RET on kidney are not clear, we assessed the effects of progressive RET in renal function, and found that proteinuria (Figure 2B) was markedly reduced in exercised diabetic group $(15.83 \pm 2.6 \mathrm{mg} / 24 \mathrm{~h})$ when compared to diabetic group $(37.66 \pm 3.2 \mathrm{mg} / 24 \mathrm{~h}, \mathrm{p}<0.001)$. Also, we evaluated podocin protein expression and observed that it was decreased in non-exercised diabetic group, while progressive RET significantly increased the expression of this protein in exercised diabetic group (Figure 2C; $\mathrm{p}<0.05$ ).

PI3K/Akt-signaling pathway was decreased in diabetic exercised animals following progressive RET

Because kidney weight was decreased in exercised diabetic group
(Figure 2A), we assessed PI3K/Akt-signaling pathway that is involved in cell growth, in order to explore the effects of progressive RET on diabetes. We found that in exercised diabetic group PI3K expression was decreased by progressive RET (Figure $3 \mathrm{~A} ; \mathrm{p}<0.01$ ) similar to what was observed for Akt phosphorylation (Figure 3B; $\mathrm{p}<0.01$ ) when compared to non-exercised diabetic group. We also evaluated renal $4 \mathrm{EBP} 1$ activation (Figure $3 \mathrm{C} ; \mathrm{p}<0.001$ ) and found that progressive RET decreased its expression in exercised diabetic group. Additionally, we measured TGF- $\beta 1$ (Figure 4) and found that progressive RET in diabetic animals $(325.8 \mathrm{pg} / \mathrm{mL})$ have decreased TGF- $\beta 1$ concentration when compared to non-exercised diabetic animals $(437 \mathrm{pg} / \mathrm{mL}, \mathrm{p}<0.05)$.

\section{Progressive RET did not preserved skeletal muscle function in diabetic trained animals}

Markedly loss of body weight is a characteristic set from STZinduced diabetic rats. As showed in Table 1, diabetic animals showed decreased body weight when compared to controls groups (exercised or not); additionally, exercised diabetic animals do not increased $(\mathrm{p}>0.05)$ body weight after 8 weeks of progressive RET. Although, RET is
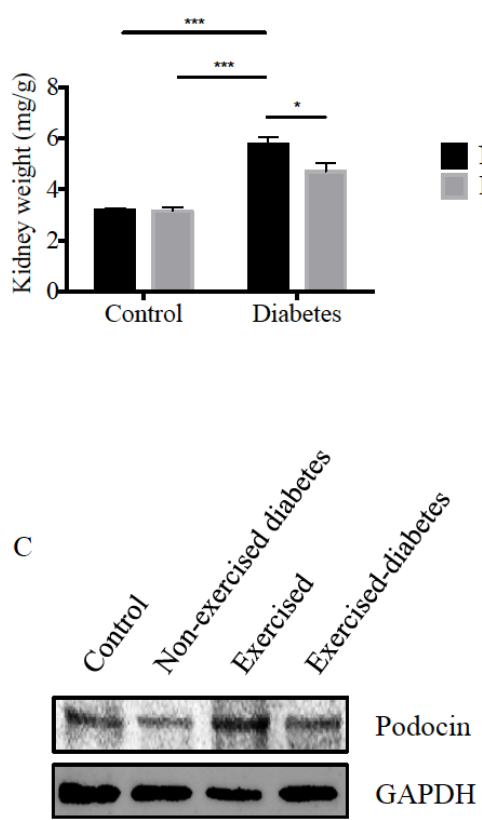

Non-exercised Exercised

B

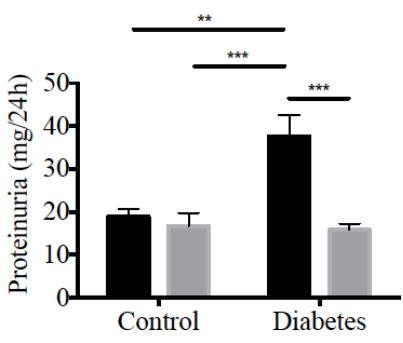

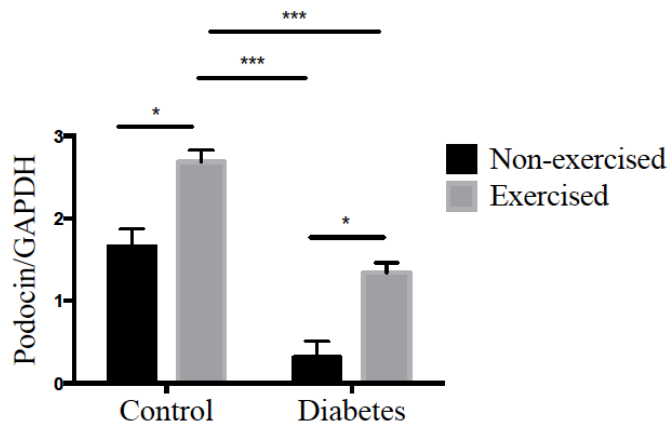

Figure 2: Effects of progressive resistance exercise training performed for 8 weeks on kidney. A) Kidney weight corrected by body weight was lower in exercised diabetic animals after progressive resistance exercise training; B) Progressive resistance exercise training decreased proteinuria in exercised diabetic animals; C) Protein expression of podocin was lower in diabetic animals when compared to exercised diabetic animals (5 animals/group). Data are reported as means \pm SEM. Two way ANOVA, ${ }^{*} p<0.05,{ }^{* *} p<0.01,{ }^{* * *} p<0.001$.

\begin{tabular}{|l|c|c|c|}
\hline & C & D & CT \\
\hline Body weight $(\mathbf{g})$ & $450 \pm 23$ & $297 \pm 15$ & $417 \pm 19^{*}$ \\
\hline Creatinine Clearance (mg/24h) & $1.02 \pm 0.1$ & $2.54 \pm 0.8$ & $1.09 \pm 0.5^{\star}$ \\
\hline Glycemia (mg/dL) & $102 \pm 9$ & $522 \pm 10$ & $95 \pm 3^{*}$ \\
\hline EDL (mg/g) & $0.4115 \pm 0.09$ & $0.368 \pm 0.04$ & $0.433 \pm 0.01^{*}$ \\
\hline Plantar (mg/g) & $0.934 \pm 0.09$ & $0.746 \pm 0.01$ & $1.048 \pm 0.11^{*}$ \\
\hline Maximal loading test (g) & $504 \pm 29$ & $419 \pm 17$ & $0.338 \pm 0.09$ \\
\hline
\end{tabular}

Table 1: Body weight, creatinine clearance, fasting blood glucose, skeletal muscle weight, and maximal load test were measured after 8 weeks of progressive exercise training. Diabetic groups showed lower body no difference (4 to 6 animals/group). Data are reported as means \pm SEM. Two way ANOVA, ${ }^{*} p<0.05$ CT vs. DT; ${ }^{* *} p<0.05 \mathrm{D}$ vs. DT. 

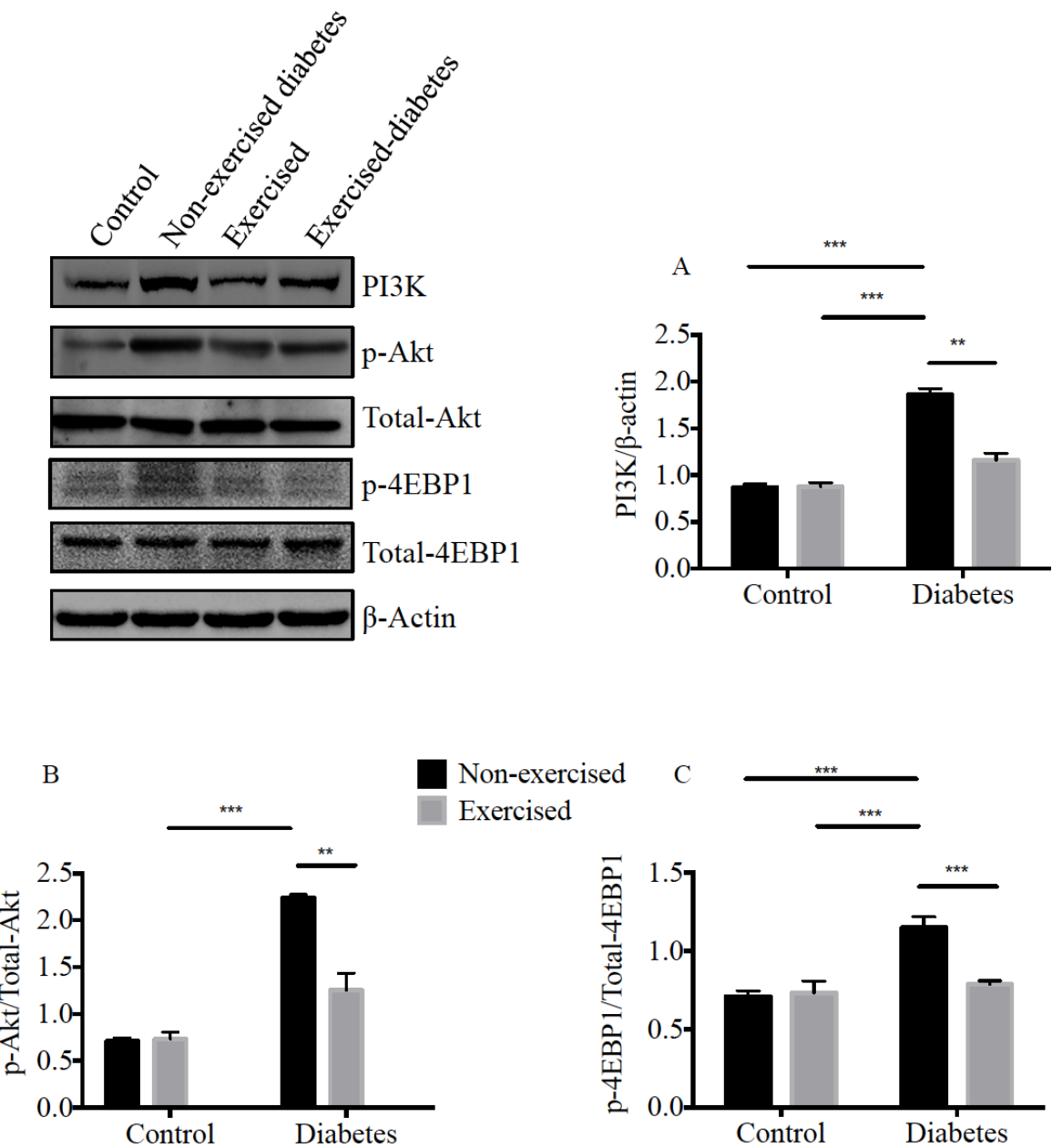

Non-exercised

Exercised

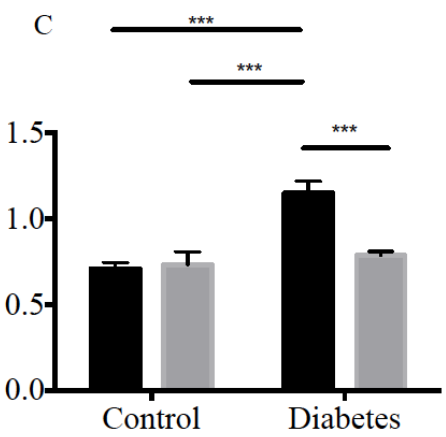

Figure 3: Mechanistic target of rapamycin (mTOR) signaling pathway was measured in kidney after progressive resistance exercise training. Upstream of mTOR A) $\mathrm{PI} 3 \mathrm{~K}$ and B) p-Akt showed higher protein expression in diabetic animals and both PI3K and p-Akt were lower expressed in exercised diabetic animals. C) p-4EBP1 demonstrated higher activation in diabetic group, while in exercised diabetic group, protein expression of p-4EBP1 were lower compared to diabetic group (5 animals/ group). Data are reported as means \pm SEM. Two way ANOVA, ${ }^{* *} p<0.01,{ }^{* * *} p<0.001$.

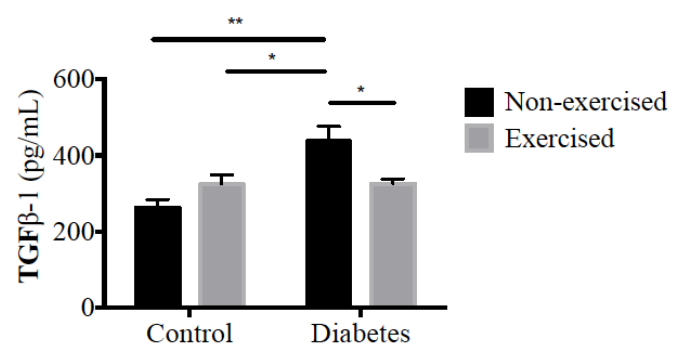

Figure 4: Transforming growth factor beta 1 (TGF $\beta$-1) was assessed by multiplex assay technology. The quantification showed decreased protein level in kidney from exercised diabetic animals ( 5 animals/group). Data are reported as means \pm SEM. Two way ANOVA, ${ }^{*} p<0.05,{ }^{* *} p<0.01$

traditionally performed to increase muscle mass, surprisingly, we found that progressive RET was not able to increase muscle weight of extensor digitorium longus (EDL) and plantaris in exercised diabetic animals $(\mathrm{p}<0.05)$. Also, characteristic gain of muscle force after RET was not statistic significantly between diabetic groups $(p>0.05)$. Moreover, these outcomes were independently of blood glucose level ( $p>0.05)$.

\section{Discussion}

Resistance exercise training adaptations include increased muscle mass and function (i.e. force); it may occur in physiological or pathophysiological conditions such as, diabetes and CKD [11-13]. Using STZ-induced diabetes model we observed that skeletal muscle mass and force were not improved by progressive RET program applied in this study. However, there was observed a significant beneficial influence of progressive RET on kidney weight and proteinuria of exercised diabetic animals. Additionally, podocin expression was assessed and it was found increased in exercised diabetic animals when compared to non-exercised diabetic animals (Figure 2), which could be responsible for normalized proteinuria in exercised diabetic animals after 8 weeks progressive RET. This is relevant because podocyte is an important structure of glomeruli barrier, and preservation of podocyte integrity is imperative to avoid protein loss through glomerular membrane $[1,8,17,18]$.

$\mathrm{PI} 3 \mathrm{~K} / \mathrm{Akt} / \mathrm{mTOR}$-signaling pathway might be related with these adaptations and is crucial for understanding the complex mechanisms related to increased kidney weight and diabetes complications. In this 
Citation: Silva KAS, de Alcântara Santos R, Arlotti MR, Jorge L, da Silva Luiz R, et al. (2014) Progressive Resistance Exercise Training Attenuated Renal Damages, but did not improve Muscle Force in STZ-Induced Diabetic Rats. J Diabetes Metab 5: 461 doi:10.4172/2155-6156.1000461

Page 5 of 6

study, kidney weight gain could be correlated to augmented expression of PI3K, p-Akt and p-4EBP1; also quantification of TGF $\beta-1$ in kidney was found increased in non-exercised diabetic animals. Potential effects of progressive RET were noticed and we observed attenuated and significant levels of protein expression (PI3K, p-Akt and p-4EBP1, and TGF $\beta$ - 1 concentration) in kidney from exercised diabetic animals after 8 weeks of exercise. These outcomes suggest that progressive RET under 50 to $80 \%$ of maximal loading test improves renal system, however does not avoids diabetes-induced damage in skeletal muscle.

Mechanisms related to renal hypertrophy have been described in the literature. In compensatory renal hypertrophy by unilateral nephrectomy, the remaining kidney increases size and activation of mTOR is the main mechanism responsible for hypertrophy. Additionally, using rapamycin it could be blocked [18]. In DN, it has been shown that rapamycin was able to delay the progression of renal hypertrophy [19].

Catabolic condition-induced skeletal muscle atrophy, such as diabetes and CKD, normally lead skeletal muscle to loss of muscle weight and function, and this is at least in part due to increased inflammation and insulin resistance $[10,20-23]$. As we known, activation of muscle fibers by resistance exercise training (RET) or injury may increase mTORC1 activation improving protein synthesis and regulating several cellular process including translation and transcription $[2,10,24]$. On the other hand, atrophy process is provided by increased atrophic factors and decreased hypertrophy factors [10]. Protein breakdown may be increased through the activation of the ubiquitin-proteasome system that is markedly involved in muscle atrophy increasing mRNA and proteins known as atrogenes such as, MuRF1 and Atrogin-1 [2527]. On the other hand, catabolic conditions may decrease skeletal muscle hypertrophy with no involvement of atrogenes, by decreasing activation of mTOR and its downstream, such as p70 S6K and 4EBP1 [10,21,28-31]. PI3K/Akt/mTOR-signaling pathway has been positively and extensively implicated on skeletal muscle hypertrophy under pathologic conditions. Only two weeks of muscle overload was reported to be sufficient to induce muscle hypertrophy and recruit satellite cells, which are responsible for skeletal muscle regeneration in a murine model of CKD [11]. In this study, skeletal muscle mass was not improved by progressive RET and it suggests that $\mathrm{PI} 3 \mathrm{~K} / \mathrm{Akt} / \mathrm{mTOR}$-signaling pathway was not modulated or at least was not fully activated by RET; additionally, muscle force showed no difference between diabetic groups (Table 1). The fact that rats trained 5 days per week may not be excluded to explain skeletal muscle impairment; moreover, the ACSM guidelines recommend that RET must be performed as complement to aerobic exercise training [6]. Altogether, these outcomes might explain the absence of traditional response of skeletal muscle to progressive RET protocol used in this study.

The results from our study are encouraging, because it demonstrates that RET could be an important tool to prevent the evolution of diabetic nephropathy. It is also possible that preventing urinary protein content by RET, increase the adhesion to a regular RET program. Surprisingly, our study also demonstrates that skeletal muscles were not improved by our RET regimen, it suggests that different intensity or at least other type of exercise should be incorporated into a regular exercise program. As we known, other types of exercise, such as endurance exercise, are widely applied as treatment to diabetes and CKD $[3,32,33]$. Our group has demonstrated the protective effects of endurance exercise in diabetic animals that performed 14 weeks of running training on renal function [3]. It suggest that both, RET and endurance exercise should be applied for people who have diabetes.
In summary, this study provides important information regarding renal damages in DN and beneficial effects on kidneys induced by progressive RET. Kidneys from exercised diabetic rats decreased size and proteinuria, and increased podocin expression, this may improve renal function; additionally, $\mathrm{PI} 3 \mathrm{~K} / \mathrm{Akt} / \mathrm{mTOR}$-signaling pathway modulates renal hypertrophy promoted by progressive RET. Finally, skeletal muscle from exercise diabetic animals were not improved after RET, suggesting that the prescription of RET used in this study induces different modulation among organs such as, kidneys and skeletal muscle. Different intensity of RET must be studied to provide complete beneficial effects of RET.

\section{Acknowledgments}

We would like to thank Fapesp (Sao Paulo Research Foundation, process 2011/20109-1) for supporting this research, and FOR (Oswaldo Ramos Foundation).

We also would like to thank Dr. Clara V. Razvickas for the excellent technical support.

\section{References}

1. Wild S, Roglic G, Green A, Sicree R, King H (2004) Global prevalence of diabetes: estimates for the year 2000 and projections for 2030. Diabetes Care 27: 1047-1053.

2. Bell GI, Polonsky KS (2001) Diabetes mellitus and genetically programmed defects in beta-cell function. Nature 414: 788-791.

3. Silva KA, Luiz Rda S, Rampaso RR, de Abreu NP, Moreira ÉD, et al. (2012) Previous exercise training has a beneficial effect on renal and cardiovascular function in a model of diabetes. PLoS One 7: e48826.

4. Inoki K, Kim J, Guan KL (2012) AMPK and mTOR in cellular energy homeostasis and drug targets. Annu Rev Pharmacol Toxicol 52: 381-400.

5. Laplante M, Sabatini DM (2012) mTOR signaling in growth control and disease Cell 149: 274-293.

6. Inoki K, Huber TB (2012) Mammalian target of rapamycin signaling in the podocyte. Curr Opin Nephrol Hypertens 21: 251-257.

7. Taniguchi CM, Tran TT, Kondo T, Luo J, Ueki K, et al. (2006) Phosphoinositide 3-kinase regulatory subunit p85alpha suppresses insulin action via positive regulation of PTEN. Proc Natl Acad Sci U S A 103: 12093-12097.

8. Inoki K, Guan KL (2006) Complexity of the TOR signaling network. Trends Cell Biol 16: 206-212.

9. Coskun O, Ocakci A, Bayraktaroglu T, Kanter M (2004) Exercise training prevents and protects streptozotocin-induced oxidative stress and beta-cell damage in rat pancreas. Tohoku J Exp Med 203: 145-154.

10. Glass DJ (2003) Signalling pathways that mediate skeletal muscle hypertrophy and atrophy. Nat Cell Biol 5: 87-90.

11. Stumvoll M, Goldstein BJ, van Haeften TW (2005) Type 2 diabetes: principles of pathogenesis and therapy. Lancet 365: 1333-1346.

12. Kubica N, Bolster DR, Farrell PA, Kimball SR, Jefferson LS (2005) Resistance exercise increases muscle protein synthesis and translation of eukaryotic initiation factor 2Bepsilon mRNA in a mammalian target of rapamycindependent manner. J Biol Chem 280: 7570-7580.

13. Bodine SC (2006) mTOR signaling and the molecular adaptation to resistance exercise. Med Sci Sports Exerc 38: 1950-1957.

14. Hornberger TA Jr, Farrar RP (2004) Physiological hypertrophy of the FHL muscle following 8 weeks of progressive resistance exercise in the rat. Can $\mathrm{J}$ Appl Physiol 29: 16-31.

15. Ronchi FA, Irigoyen MC, Casarini DE (2007). Association of somatic and $\mathrm{N}$-domain angiotensin-converting enzymes from Wistar rat tissue with renal dysfunction in diabetes mellitus. J Renin Angiotensin Aldosterone Syst 8: 3441.

16. Szkudelski T (2001) The mechanism of alloxan and streptozotocin action in B cells of the rat pancreas. Physiol Res 50: 537-546.

17. Stumvoll M, Goldstein BJ, van Haeften TW (2008) Type 2 diabetes: pathogenesis and treatment. Lancet 371: 2153-2156. 
Citation: Silva KAS, de Alcântara Santos R, Arlotti MR, Jorge L, da Silva Luiz R, et al. (2014) Progressive Resistance Exercise Training Attenuated Renal Damages, but did not improve Muscle Force in STZ-Induced Diabetic Rats. J Diabetes Metab 5: 461 doi:10.4172/2155-6156.1000461

Page 6 of 6

18. Chen JK, Chen J, Neilson EG, Harris RC (2005) Role of mammalian target of rapamycin signaling in compensatory renal hypertrophy. J Am Soc Nephrol 16: 1384-1391.

19. Lloberas N, Cruzado JM, Franquesa M, Herrero-Fresneda I, Torras J, et al. (2006) Mammalian target of rapamycin pathway blockade slows progression of diabetic kidney disease in rats. J Am Soc Nephrol 17: 1395-1404.

20. Zhang L, Rajan V, Lin E, Hu Z, Han HQ, et al. (2011) Pharmacological inhibition of myostatin suppresses systemic inflammation and muscle atrophy in mice with chronic kidney disease. FASEB J 25: 1653-1663.

21. Zhang L, Wang XH, Wang H, Du J, Mitch WE (2010) Satellite cell dysfunction and impaired IGF-1 signaling cause CKD-induced muscle atrophy. J Am Soc Nephrol 21: 419-427.

22. Thomas SS, Dong Y, Zhang L, and Mitch WE. (2013). Signal regulatory proteinalpha interacts with the insulin receptor contributing to muscle wasting in chronic kidney disease. Kidney Int 84: 308-316.

23. Dong Y, Silva KA2, Dong Y3, Zhang L4 (2014) Glucocorticoids increase adipocytes in muscle by affecting IL-4 regulated FAP activity. FASEB $\mathrm{J}$.

24. Dominiczak MH (2003) Obesity, glucose intolerance and diabetes and their links to cardiovascular disease. Implications for laboratory medicine. Clin Chem Lab Med 41: 1266-1278.

25. Bodine SC (2013) Disuse-induced muscle wasting. Int J Biochem Cell Biol 45 2200-2208.
26. Bodine SC, Latres E, Baumhueter S, Lai VK, Nunez L, et al. (2001) Identification of ubiquitin ligases required for skeletal muscle atrophy. Science 294: 1704 1708.

27. Gomes MD, Lecker SH, Jagoe RT, Navon A, Goldberg AL (2001) Atrogin-1, a muscle-specific F-box protein highly expressed during muscle atrophy. Proc Natl Acad Sci U S A 98: 14440-14445.

28. Busquets S, Toledo M, Orpi M, Massa D, Porta M, et al. (2012). Myostatin blockage using actRIIB antagonism in mice bearing the Lewis lung carcinoma results in the improvement of muscle wasting and physical performance. J Cachexia Sarcopenia Muscle 3: 37-43.

29. Dong Y, Pan JS, Zhang L (2013) Myostatin suppression of Akirin1 mediates glucocorticoid-induced satellite cell dysfunction. PLoS One 8: e58554.

30. Fearon KC, Glass DJ, Guttridge DC (2012) Cancer cachexia: mediators, signaling, and metabolic pathways. Cell Metab 16: 153-166.

31. Lokireddy S, Wijesoma IW, Bonala S, Wei M, Sze SK, et al. (2012) Myostatin is a novel tumoral factor that induces cancer cachexia. Biochem J 446: 23-36.

32. Luiz Rda S, Silva KA, Rampaso RR, Antônio EL, Montemor J, et al. (2013) Exercise attenuates renal dysfunction with preservation of myocardial function in chronic kidney disease. PLoS One 8: e55363.

33. Bushman B (2014) Promoting exercise as medicine for prediabetes and prehypertension. Curr Sports Med Rep 13: 233-239. 